\title{
Alterations of the male and female reproductive systems induced by COVID-19
}

\author{
Paulo Roberto Carneiro Gomes - Maria Debora Rodrigues da Rocha • Francisco Alex da Rocha Coelho • \\ John Arlley Sousa Pinho de Lira - Rubens Renato de Sousa Carmo - Hélio Mateus Silva Nascimento • \\ Samara Marques de Oliveira - Wesley Rodrigues da Silva · Rebeca Galdino Medeiros · Even Herlany Pereira \\ Alves · André dos Santos Carvalho - Daniel Fernando Pereira Vasconcelos
}

Received: 15 December 2020 / Accepted: 10 April 2021 / Published online: 28 May 2021

(C) Springer-Verlag GmbH Austria, part of Springer Nature 2021

\begin{abstract}
Summary A variety of pneumonia cases of unknown cause emerged in China in December 2019. A new virus belonging to the Coronaviridae family, called severe acute respiratory syndrome coronavirus 2 (SARS-CoV-2), which causes coronavirus disease 2019 (COVID-19). Within a few days, COVID-19 became a pandemic disease. This review aimed to investigate the possible implications of COVID-19 for human reproductive systems, as in previous studies ACE2 was highly expressed in some organs of these systems, such as the testicles. A total of 41 publications were found in the specialized databases and, after selection, 7 articles were used to build this study. Our results showed that the fever caused by COVID-19 has a negative effect on spermatogenesis, there is high expression of ACE2 in the testicles and in the uterine tubes and there is a higher level of transmembrane protease serine 2 (TMPRSS2), which is also responsible for the entry of the virus into the cell. Moreover, it was noted that there was viral genetic material in the semen and an increase in the serum concentration of luteinizing hormone (LH) in men and women, which
\end{abstract}

\section{P. R. Carneiro Gomes · F. A. da Rocha Coelho · J. A. Sousa Pinho de Lira $\cdot$ R. R. de Sousa Carmo $\cdot$ S. Marques de Oliveira $\cdot$ W. Rodrigues da Silva $(\square)$ \\ Department of Biomedicine, Federal University of Parnaiba Delta (UFDPar), Parnaiba, Piauí, Brazil mr.wesleyrodrigues@gmail.com}

M. D. Rodrigues da Rocha $\cdot$ R. Galdino Medeiros Department of Physiotherapy, Federal University of Parnaiba Delta (UFDPar), Parnaiba, Piauí, Brazil

W. Rodrigues da Silva

Federal University of Piaui, Teresina, Piauí, Brazil

A. dos Santos Carvalho · D. F. Pereira Vasconcelos Laboratory of Histological Analysis and Preparation (LAPHis), Federal University of Parnaiba Delta (UFDPar), Parnaiba, Piauí, Brazil could cause hypogonadism. Thus, we conclude that there is the possibility of infection and malfunction in the reproductive organs as well as the plausibility of sexual transmission of this disease. Further analysis must be carried out to prove the effects of COVID-19 on the human reproductive systems.

Keywords Infertility $\cdot$ Pandemic $\cdot$ Reproduction $\cdot$ Virus

\section{Introduction}

The coronaviruses are a large family of viruses belonging to the family Coronaviridae, subfamily Coronavirinae and order Nidovirales, known since 1960 for causing respiratory infections in humans and animals [1, 2]. The newly identified severe acute respiratory syndrome coronavirus 2 (SARS-CoV-2) is the seventh of the family to be described associated with diseases in humans [3]. These pathogens are seen under electron microscopy as circles with spikes that end in small droplets that appear on its surface, in a shape similar to a crown [4]. The SARS-CoV-2, the agent responsible for the coronavirus disease 2019 (COVID-19), is composed of a single strand of positive sense RNA (ribonucleic acid) surrounded by a lipoprotein viral envelope, in which the spike (S) protein, activated by a cell protease, is arranged. The protein $S$ mediates viral entry into target cells by binding to a cell receptor, the angiotensin-converting enzyme 2 (ACE2). The SARS-CoV-2 makes use of Serino Protease Cell TMPRSS2 to initiate protein $\mathrm{S}$ [5-8].

The COVID-19 is an acute disease, which has an incubation time in the human body of around 4.1-7.0 days, with an average of 5.2 days, with a $95 \%$ confidence interval (CI: 4.1 to 7.0) [9]. The mode of transmission is caused by coughing, sneezing, sputum, contaminated fluids and possibly patient feces 
$[10,11]$. Transmission can occur through contamination of the hands, usually when after contamination the susceptible individual puts them in contact with the oral, nasal and/or ocular mucosa [12, 13].

A series of pneumonia cases with no known cause in Wuhan City, Hubei Province China, was reported to the World Health Organization (WHO) in December 2019. The declaration of being an international public health emergency came on 30 January 2020 and a pandemic on 11 March. The total number of cases rose rapidly and on 16 March 2020 the 167,511 confirmed cases in more than 140 countries exceeded the numbers of cases existing in the Chinese territory, considering Europe as the new epicenter of the pandemic $[14,15]$. On 21 May 2020, the Worldometer data and monitoring website recorded 5,137,481 confirmed cases worldwide, with 2,049,806 recovered and 331,499 deaths [16].

The SARS-CoV-2 may be associated with changes in several organs and systems [17]. Some studies have shown that the respiratory, cardiovascular, digestive and urinary systems are targets of infection with the new coronavirus. In addition, human reproductive systems and functions have been reported as potential targets of infection [18]. The patients of senile age and/or with comorbidities are susceptible to infection and prone to the most severe forms, which may be associated with acute respiratory distress syndrome (ARDS) and with a so-called cytokine storm. They may, therefore, present a worse prognosis for the disease [19].

In a review [20] a variety of studies were found that indicated the presence of abnormal kidney function or even kidney damage. After analysis the results showed that $\mathrm{ACE}_{2}$ is expressed in different amounts in each human organ and has high expression in renal tubular cells, Leydig cells and seminiferous tubules in the testes. It was argued that SARS-CoV and SARS-CoV-2 share the same $\mathrm{ACE}_{2}$ receptor, that previous research showed that orchitis is a complication of SARS infection and that spermatogenesis can be affected. As a result, SARS-CoV-2 can cause infertility, a problem that requires a lot of attention especially among young men. In addition to the potential damage generated by the virus, the toxicity levels of antiviral drugs to the kidneys must be considered.

Similarly, it can occur in the female reproductive system [21] addressed the availability of ACE2 in host cells of the female reproductive system, such as in the ovaries, uterus, vagina and placenta. Furthermore, based on previous studies Jing et al. [21] listed some functions of the enzymes for which ACE2 modulates levels of angiotensin 2 and angiotensin (1-7). Due to these functional characteristics, SARS-CoV-2 can cause disturbance in female reproductive functions through the regulation of ACE2. Thus, this study focused on analyzing the possible effects of SARS-CoV-2 and the disease caused by it (COVID-19) on human male and female reproductive organs.

\section{Methodology}

This is a systematic review of the effects of the SARS$\mathrm{CoV}-2$ virus and the disease for which it is responsible, COVID-19, for the human male and female reproductive systems.

Search strategy: to conduct this review study, PubMed, Bireme and Scopus databases were searched using the specific descriptors: "genitalia", "coronavirus infection" and "2019-nCoV", combined with each other and with Boolean operators. There was a language restriction in the search for studies for the English language and time, considering articles published between December 2019 and May 2020 and that addressed the proposed topic. Reading the abstracts and references was recommended to search for potentially relevant studies.

Inclusion criteria: studies that were relevant to the construction of this work and related to the effects of COVID-19 on the organs of the human male and female reproductive systems were included. Interviews, studies that addressed the correlation between COVID-19 and STDs (Sexually Transmitted Diseases) and studies that do not provide sufficient data for the preparation of the work and were not related to the topic, were excluded.

Data extraction: the use of a standard form consisting of the following topics was established: first author and year of publication, title of work, methodology used, results found and conclusion of studies [22].

\section{Results}

The bibliographic search resulted in 41 published articles. Of these 17 were excluded due to duplication in the bibliographic databases, 17 studies were not considered for this review as they did not fit the topic in question. The remaining 7 articles published in 2020 were used for this production, which presented the possible implications of SARS-CoV-2 in the male and female reproductive systems (Fig. 1). These articles are best described in Table 1, which contains the titles of the article, name of the first author, date of publication, methodology applied in the study and the main conclusions.

\section{Discussion}

The importance of this review is based on demonstrating, through data from the literature, the possible changes in the human reproductive system caused by COVID-19 and in this way motivating research on the topic addressed. The infectious disease caused by the new coronavirus has spread rapidly all over the world causing thousands of deathes, affecting the health system and the global economy, which could cause a drop in the world gross domestic product (GDP) from $2.9 \%$ to $2.4 \%[11,27]$. According to the 
Fig. 1 Flow diagram: identification, screening, eligibility and analysis of studies included in the literature review

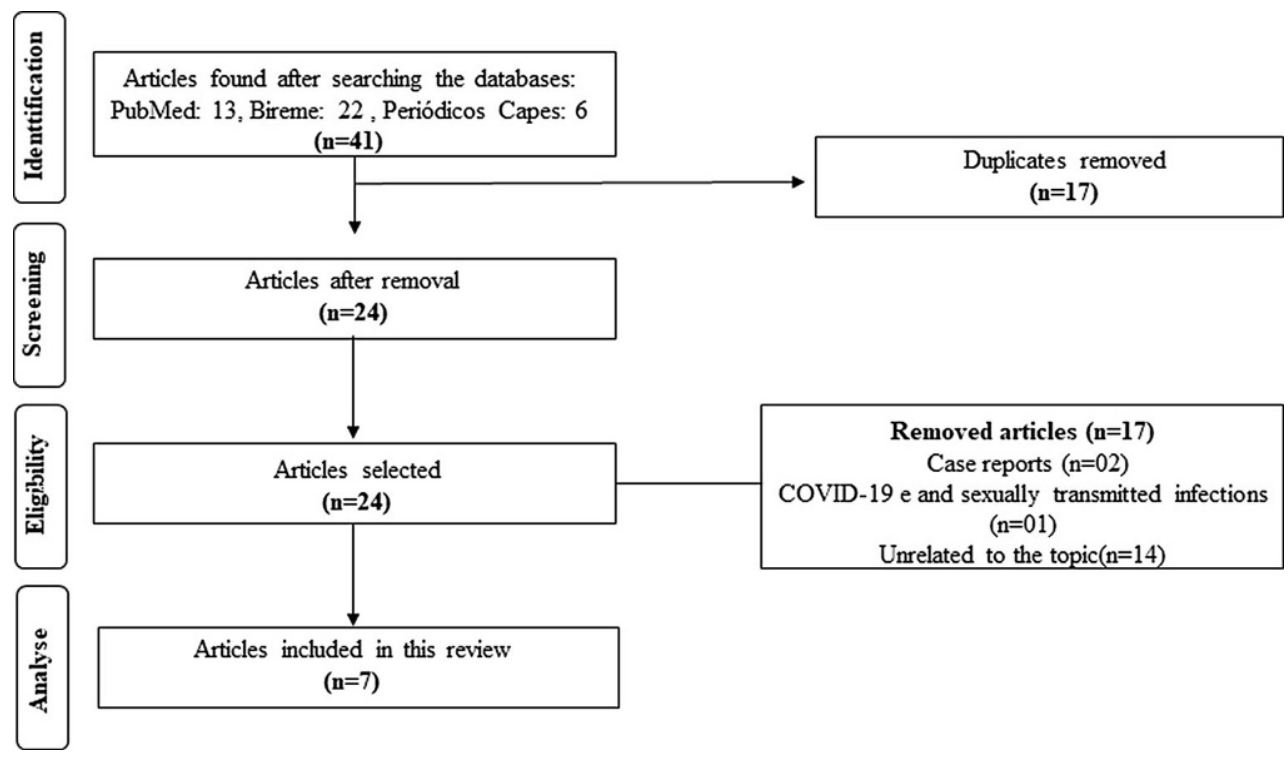

results found, the literature presents evidence that the pathogen that causes this disease affects several systems of the human organism, including the reproductive system.

According to Segars et al. [25] it was noted that the fever caused by COVID-19 negatively affects spermatogenesis, decreasing the concentration of sperm and impairing the mobility of these cells. An experimental study carried out in mice reported that hyperthermia causes serious damage to the sperm formation process, such as damage to the head and tail. The animals were divided into groups and subsequently exposed to different temperatures $\left(20\right.$ and $\left.36^{\circ} \mathrm{C}\right)$. In view of the results, it was possible to observe that the mice exposed to a high temperature had higher testicular weight, lower concentration of gametes, increased diameter and loss of seminiferous tubule epithelium in addition to lower sperm motility. Furthermore, it has been noted that high temperatures damage sperm chromatin and cause sperm damage in its various stages of development [28].

The SARS-CoV-2 virus is known to use ACE2 receptors to enter human cells; however, TMPRSS2 expression is also a target of the virus to infect human cells $[25,26]$. Studies reported that it is possible to identify ACE2 in the male and female reproductive systems, having a greater expression of this enzyme in testicular cells, mainly in Leydig cells, spermatogonia and Sertoli cells $[20,23,26]$. In this context, an experiment that proposed to investigate the level of expression of ACE2 and TMPRSS2 in cells of different organs of the human systems, using the scRNA-seq data, demonstrated a significant proportion of these enzymes in human testicles. Based on the results, it was possible to group the organs with the highest risk of being affected by the virus. Among them are the lungs and testicles with the highest expression of ACE2. The lungs, large intestine, fallopian tubes and nasal airways, on the other hand, showed greater expression of TMPRSS2. Thus, it is possible to verify that the organ that has the highest risk of suffering injury by SARS-CoV-2 is the lungs. Then, with a high level of injury comes the testicles, followed by the organs of the digestive system, brain and heart. It has also been reported that there is a low expression of ACE2 in cells of the ovary and uterus [17, 21] demonstrated, through GeneCards that there is a significant presence of ACE2 receptors in ovarian cells, indicating that the organ may be a potential target for COVID-19.

The presence of ACE2 was verified in sperm cells through immunohistochemistry, concluding again that the testes may be the target of infection by the new coronavirus. This same study conducted a search of 112 patients diagnosed with COVID-19, whose objective was to analyze whether they had any symptoms in their reproductive organs. Based on this 3 of these patients with severe COVID-19, presented with orchidoptosis for 3 days. Then, a screening was carried out for the presence of SARS-CoV-2 nRNA in the semen of 17 patients in need of fertility and 9 showed positive results, demonstrating the presence of the genetic material of the virus in the semen [24].

Liu et al. [26] reported in their studies that patients with SARS-CoV-2 had a higher concentration in serum levels of luteinizing hormone (LH). The $\mathrm{LH}$ is active in the fertility of men and women acting on the gonads, assisting in the production of sex hormones and gametes [29]. In high quantities, LH can lead to testicular dysfunction and changes in testosterone concentration [30]. Thus, it was concluded that the virus can cause the malfunction of the reproductive glands (hypogonadism). A search for expression of ACE2 in primordial germ cells through tissues of the testicles of male donors was also carried out. During the experiment, ACE2 expression was compared in two healthy patients with different ages ( 30 and 60 years old) and 


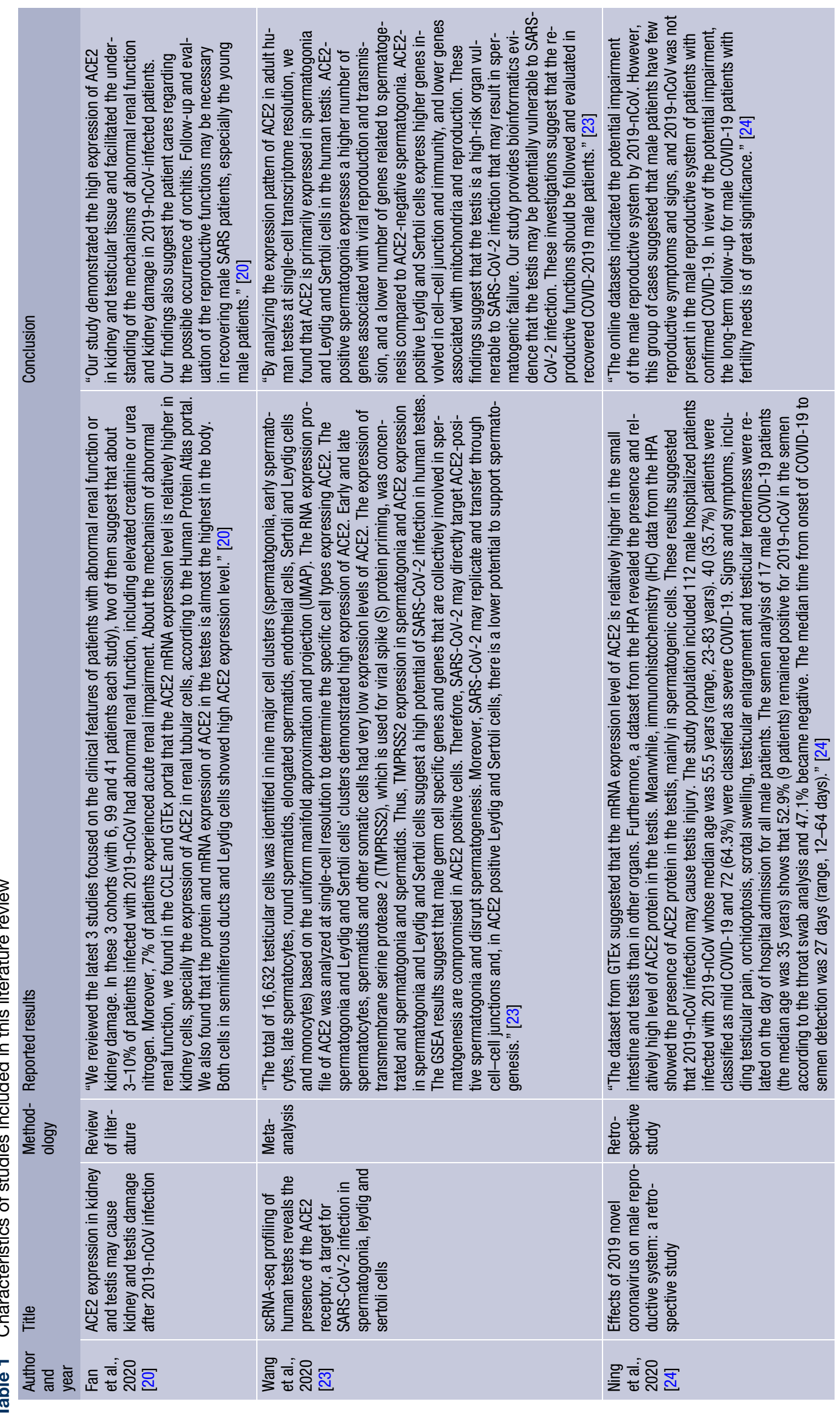




\section{review article}

\begin{tabular}{|c|c|c|c|c|c|}
\hline & 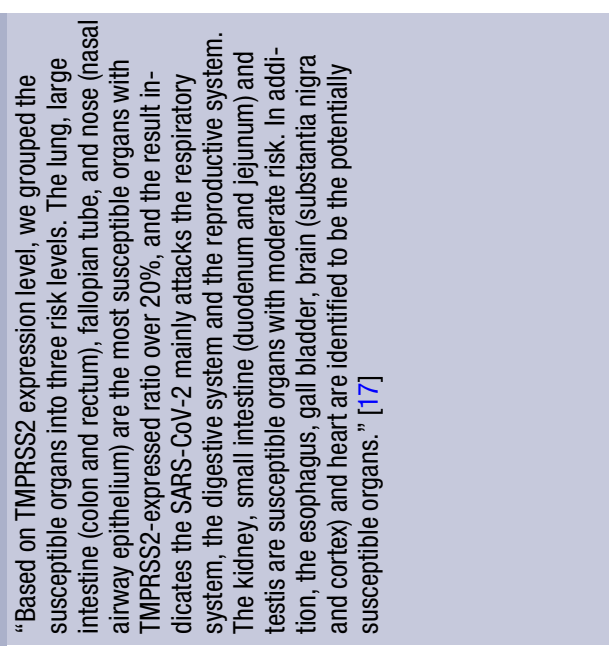 & 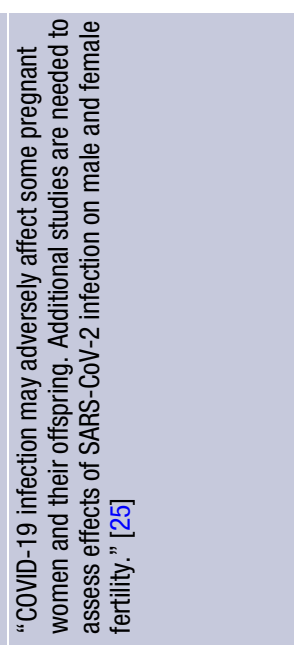 & 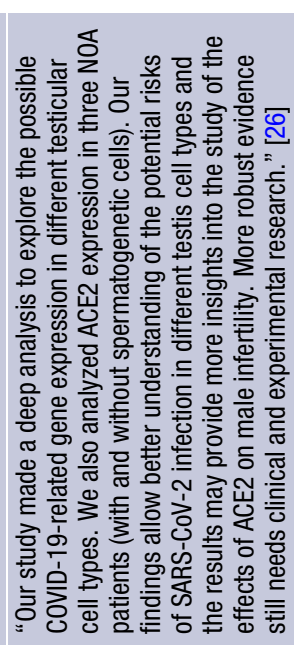 & 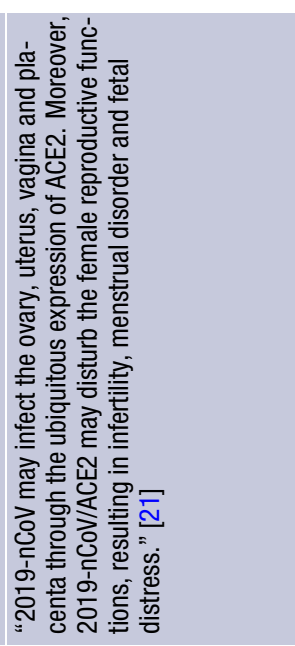 & \\
\hline & 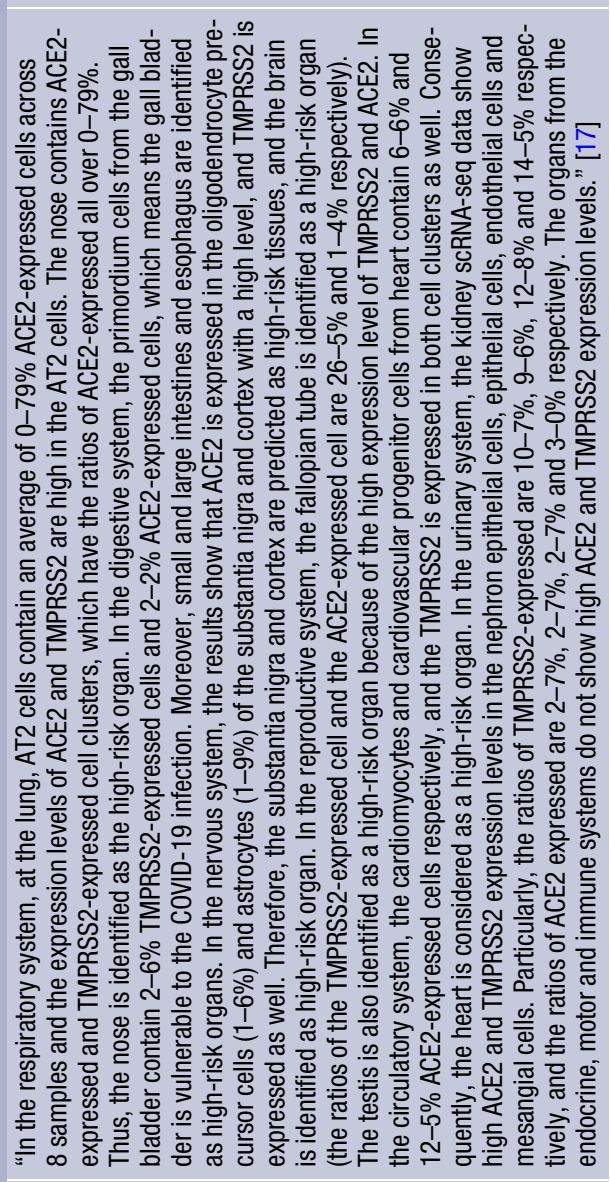 & 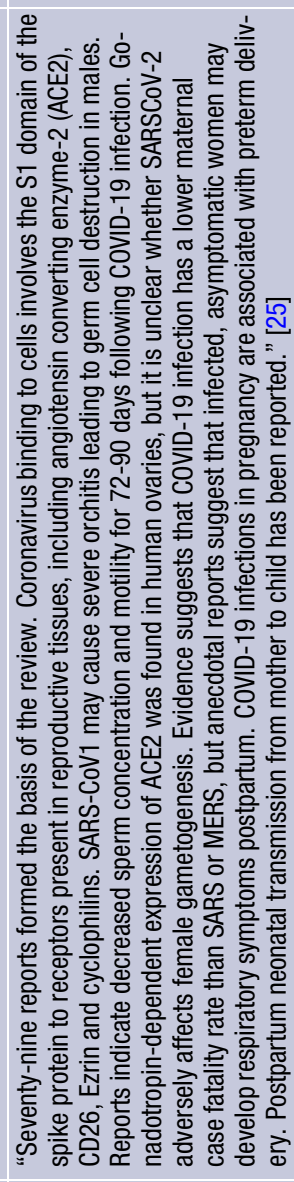 & 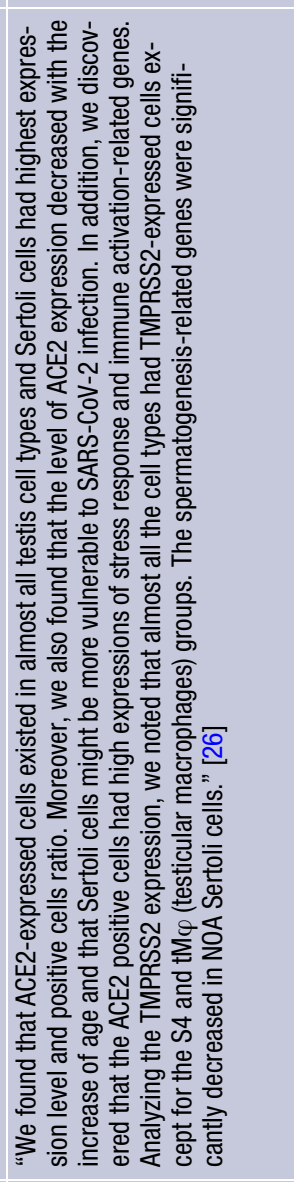 & 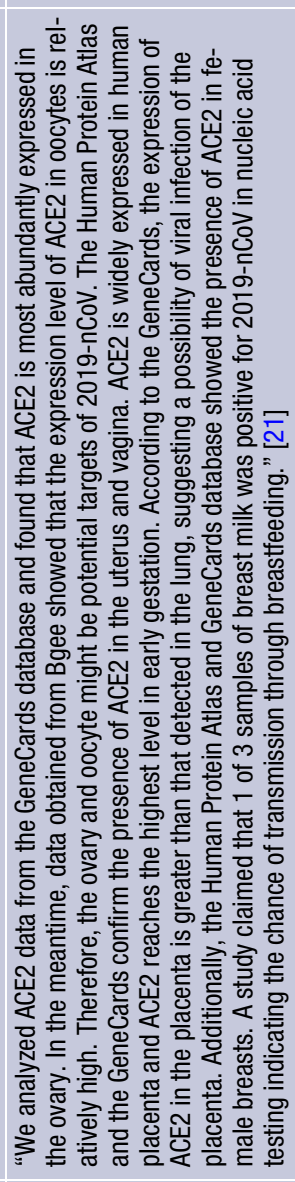 & \\
\hline 흥 & 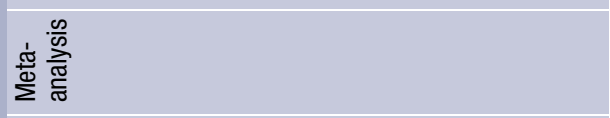 & 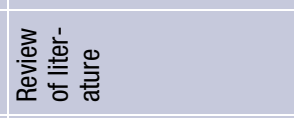 & 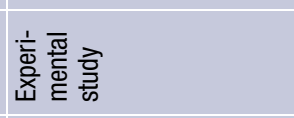 & 产高 & \\
\hline & 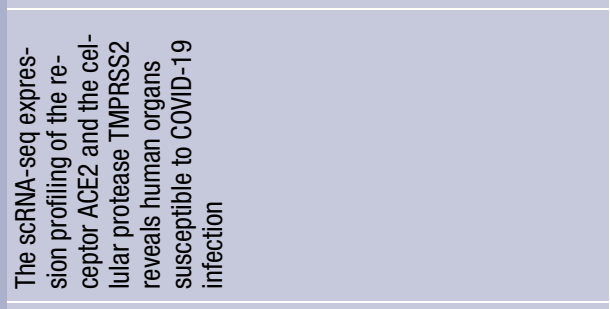 & 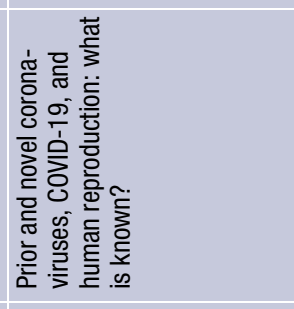 & 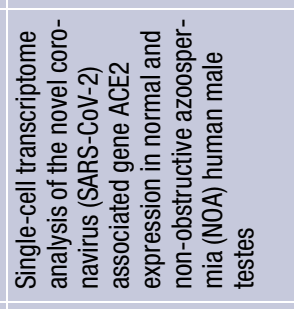 & 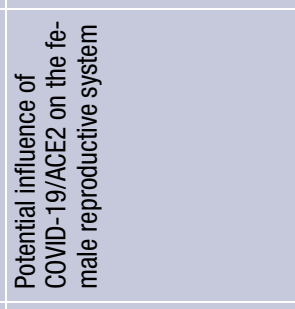 & \\
\hline 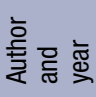 & б & 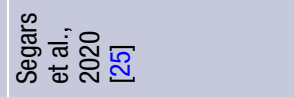 & 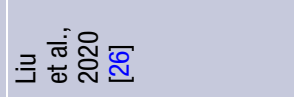 & 옥 & \\
\hline
\end{tabular}


a greater presence of this enzyme was observed in the 30-year-old patient, demonstrating that the presence of ACE2 may be related to age, decreasing during adulthood [26]. A study sought to justify the ancestry of SARS in young people and aimed to relate ACE2 as a viral receptor and age. The research was carried out with young and old rats and at the end it was possible to observe that in the older rats, the expression of the enzyme was significantly decreased and that the syndrome can affect the young age group [31]. Thus, SARS-CoV-2 may cause greater reproductive harm in younger people.

\section{Conclusion}

Therefore, it was noted that SARS-CoV-2 receptors, such as ACE2 and TMPRSS2, are found in organs of the various systems of the human body. Thereby, through COVID-19 studies and symptomatology it is possible to highlight that the respiratory system, which has a large expression of the viral receptors, is the most affected. In this perspective, our review found that the human reproductive system also has a significant expression of ACE2 and TMPRSS2, demonstrating a possible infection in the primordial germ cells. This cellular invasion causes a malfunction of the reproductive glands and a possible alteration in the gametes; however, there must be more analytical studies to prove the action of COVID-19 in the reproductive system and a possible transmission of the disease through sex.

Conflict of interest P.R. Carneiro Gomes, M.D. Rodrigues da Rocha, F.A. da Rocha Coelho, J.A. Sousa Pinho de Lira, R.R. de Sousa Carmo, H.M. Silva Nascimento, S. Marques de Oliveira, W. Rodrigues da Silva, E.H. PereiraAlves, A. dosSantos Carvalho, R. Galdino Medeiros and D.F. Pereira Vasconcelos declare that they have no competing interests.

\section{References}

1. Cui J, Li F, Shi Z. Origin and evolution of pathogenic coronaviruses. Nat Rev Microbiol. 2019;17:181-92. https:// doi.org/10.1038/s41579-018-0118-9.

2. Pascoal DB, Carvalho ACS, Mata LELFS, Lopes TP, Lopes LP, da Cruz CM. Síndrome Respiratória Aguda: uma resposta imunológica exacerbada ao COVID19. Brazilian J Health Rev. 2020;3(2):2978-94. https://doi.org/10.34119/ bjhrv3n2-138.

3. Zhu N, Zhang D, Wang W, Li X, Yang B, Song J, et al. A novel coronavirus from patients with pneumonia in China. N Engl J Med. 2019;2020(382):727-33. https://doi.org/10. 1056/NEJMoa2001017.

4. Li G, Fan Y, Lai Y, Han T, Li Z, Zhou P, et al. Coronavirus infections and immune responses. J Med Virol. 2020;92(4):424-32. https://doi.org/10.1002/jmv.25685.

5. Li W, Moore MJ, Vasilieva N, Su J, Wong SK, Berne MA, et al. Angiotensin-converting enzyme 2 is a functional receptor for the SARS coronavirus. Nature. 2003;426(6965):450-4. https://doi.org/10.1038/nature02145.

6. Glowacka I, Bertram S, Müller MA, Allen P, Soilleux E, PfefferleS, etal. Evidence thatTMPRSS2 activates the severe acute respiratory syndrome coronavirus spike protein for membrane fusion and reduces viral control by the humoral immune response. JVirol. 2011;85(9):4122-34. https:// doi. org/10.1128/JVI.02232-10.

7. ShullaA, Heald-SargentT, Subramanya G,ZhaoJ,PerlmanS, Gallagher T. A transmembrane serine protease is linked to the severeacuterespiratorysyndrome coronavirus receptor and activates virus entry. JVirol. 2011;85(2):873-82. https:// doi.org/10.1128/JVI.02062-10.

8. Wu YC, Chen CS, Chan YJ. The outbreak of COVID-19: An overview. J Chin Med Assoc. 2020;83(3):217-20. https:// doi.org/10.1097/JCMA.0000000000000270.

9. Li Q, Guan X, Wu P, Wang X, Zhou L, Tong Y, et al. Early transmission dynamics in Wuhan, China, of novel coronavirusinfected pneumonia. N Engl J Med. 2020;382:1199-207. https://doi.org/10.1056/NEJMoa2001316.

10. Huang C, Wang Y, Li X, Ren L, Zhao J, Hu Y, et al. Clinical features of patients infected with 2019 novel coronavirus in Wuhan, China. Lancet. 2020;395(10223):497-506. https:// doi.org/10.1016/S0140-6736(20)30183-5.

11. Chen N, Zhou M, Dong X, Qu J, Gong F, Han Y, et al. Epidemiological and clinical characteristics of 99 cases of 2019 novel coronavirus pneumonia in Wuhan, China: a descriptive study. Lancet. 2020;2(0):30211-7. https:// doi. org/10.1016/S0140-6736.

12. Singhal T. A review of coronavirus disease-2019 (COVID19). Indian J Pediatr. 2020;87:281-6. https://doi.org/10. 1007/s12098-020-03263-6.

13. World Health Organization. World Health Organization. Situation reports.. https://www.who.int/emergencies/ diseases/novel-coronavirus-2019/situation-reports/. Accessed 22 May 2020.

14. World Health Organization. World Health Organization. Events as they happen. 2020. https://www.who.int/ emergencies/diseases/novel-coronavirus-2019/eventsas-they-happen. Accessed 21 May 2020.

15. Tang K, Gaoshan J, Ahonsi B, Ali M, Bonet M, Broutet N, et al. Sexual and reproductive health (SRH): a key issue in the emergency response to the coronavirus disease (COVID19) outbreak. Reprod Health. 2020;17:1-3. https://doi.org/ 10.1186/s12978-020-0900-9.

16. https://www.worldometers.info/coronavirus $/$ ?fbclid= IwAR19og43nWLhrj3zfKmxPl5 mXk7LSHvCNN26PvKXsCiKFEASChMEVJo5qM

17. QiJ,ZhouY,HuaJ,ZhangL, Bian J, LiuB, etal. The scRNA-seq expression profiling of the receptor ACE2 and the cellular protease TMPRSS2 reveals human organs susceptible to COVID-19 infection. BioRxiv. 2020; https://doi.org/10. $1101 / 2020.04 .16 .045690$.

18. Zou X, Chen K, Zou J, Han P, Hao J, Han Z. Single-cell RNAseq data analysis on the receptor ACE2 expression reveals the potential risk of different human organs vulnerable to 2019-nCoV infection. Front Med. 2020;14(2):185-92. https://doi.org/10.1007/s11684-020-0754-0.

19. Guo YR, Cao QD, Hong ZS, Tan YY, Chen SD, Jin HJ, et al. The origin, transmission and clinical therapies on coronavirus disease 2019 (COVID-19) outbreak-anupdate on the status. Military Med Res. 2020;7(1):1-10. https:// doi. org/10.1186/s40779-020-00240-0.

20. Fan C, LiK, DingY, Lu WL, Wang J.ACE2 expression in kidney and testis may cause kidney and testis damage after 2019ncoV. Infect Medrxiv. 2020; https://doi.org/10.1101/2020. 02.12.20022418.

21. JingY, Run-Qian L, Hao-Ran W, Hao-Ran C, Ya-Bin L, YangG, et al. Potential influence of COVID-19/ACE2 on the female reproductive system. Mol Hum Reprod. 2020; https://doi. org/10.1093/molehr/gaaa030. 
22. Brito LFND, Mendes TE, Lima APB, Pedrin RRDA, Santos CN, Paranhos LR. Influência do tratamento ortodôntico na reabsorção radicular: uma revisão sistemática. Revista DaFaculdade DeOdontol-UPF. 2016;21(2:231-6.

23. Wang $\mathrm{Z}$, Xu X. scRNA-seq profiling of human testes reveals the presence of the ACE2 receptor, A target for SARScoV-2 infection in spermatogonia, leydig and sertoli. Cells. 2020;920:1-9. https://doi.org/10.3390/cells9040920.

24. Ning J, Li W, Ruan Y, Xia Y, Wu X, Hu K, et al. Effects of 2019 novel coronavirus on male reproductive system: a retrospective study. Preprints. 2020; https://doi.org/10. 20944/preprints202004.0280.vl.

25. Segars J, Katler Q, McQueen DB, Kotlyar A, Glenn T, Knight Z, et al. Prior and novel Coronaviruses, COVID19, and human reproduction: what is known? Fertil Steril. 2020;113(6):1140-9. https://doi.org/10.1016/j.fertnstert. 2020.04.025.

26. Liu X, Chen Y, Tang W, Zhang L, Chen W, Yan Z, et al. Singlecell transcriptome analysis of the novel coronavirus (SARSCoV-2) associated gene ACE2 expression in normal and non-obstructive azoospermia (NOA) human male testes. Sci China Life Sci. 2020; https://doi.org/10.1007/s11427020-1705-0.

27. Bobdey S, Ray S. Going viral-Covid-19 impact assessment: a perspective beyond clinical practice. J Mar Med Soc.
2020;22:9-12. https://doi.org/10.4103/jmms.jmms_12_ 20.

28. Kastelic JP, Wilde RE, Bielli A, Genovese P, Rizzoto G, Thundathil J. Hyperthermia is more important than hypoxia as a cause of disrupted spermatogenesis and abnormal sperm. Theriogenology. 2019;131:177-81. https://doi.org/ 10.1016/j.theriogenology.2019.03.040.

29. Nedresky D, Singh G. Physiology, Luteinizing Hormone. StatPearls Publishing.. https://www.ncbi.nlm.nih.gov/ books/NBK539692/. Accessed 22 May 2020.

30. Rodger RS, Morrison L, Dewar JH, Wilkinson R, Ward MK, Kerr DN. Perda da secreção do hormônio luteinizante pulsátil em homens com insuficiência renal crônica. BMJ. 1985;291(6509):1598-600. https://doi.org/10.1136/bmj. 291.6509.1598.

31. Xie X, Chen J, Wang X, Zhang F, Liu Y. Age- and genderrelated difference of ACE2 expression in rat lung. Life Sci. 2006;78:2166-71. https://doi.org/10.1016/j.lfs.2005. 09.038.

Publisher's Note Springer Nature remains neutral with regard to jurisdictional claims in published maps and institutional affiliations. 